\title{
Histopathological Examination of Uterine Evacuation Products Following First Trimester Abortion Along with Clinico-Pathological Correlation in A Tertiary Care Centre - A Descriptive Study
}

\author{
Dhruvi Shah and Riti T.K Sinha*
}

Department of Pathology, Gujarat Adani Institute of Medical Sciences, Bhuj, Gujarat, India.

\begin{abstract}
Background: Spontaneous abortion also known as miscarriage is one of the most common conditions encountered by the gynecologists and obstetricians. The women who had spontaneous miscarriage have traditionally undergone surgical uterine evacuation of retained products of conception. In recent years more and more patients are evaluated with more and more refined diagnostic techniques and therapeutic interventions. In our center too, it is a routine practice to submit tissues obtained by uterine evacuation to the histopathology department, and to confirm intrauterine fetal tissue.
\end{abstract}

Methods: The present retrospective study was done for a period of one year in the department of Pathology, Gujarat Adani institute of medical sciences, G. K General Hospital, Bhuj. Total 62 samples of uterine evacuation products were evaluated. Along with their clinicopathological correlation the histopathological spectrum of the lesions were also studied and the necessary statistical analysis was done.

Result: The most common clinical diagnosis was retained product of conception (34\%), followed by hydatidiform mole (24\%). The most common histological finding was presence of chorionic villi (55\%), followed by presence hydatidiform mole (24\%). Clinico-pathological correlation was found in $(79 \%)$.

Conclusion: The present study was to highlight the importance of histopathological evaluation of the uterine evacuation products. Our study strongly recommends the histopathological examination of all uterine evacuation products as it aids in timely management of the patients.

Keywords: Histopathological Spectrum, First Trimester Abortion , Product of Conception

\section{Introduction}

Spontaneous abortion also known as miscarriage is one of the most common conditions encountered by the gynecologists and obstetricians. The women who had spontaneous miscarriage have traditionally undergone surgical uterine evacuation of retained products of conception. In recent years more and more patients are evaluated with more and more refined diagnostic techniques and therapeutic interventions. Histopathological examination of product of conception in pregnancy failure is an integral component of the management. Bleeding and early pregnancy loss presents the most common problem dealt in the first trimester of the pregnancy. ${ }^{[1]}$ Two reasons mandate the histopathological examination of uterine evacuation products, one to evaluate the presence of intra uterine gestation and second to exclude some diseases mainly gestational trophoblastic diseases like molar pregnancy or to some extent carcinomas. ${ }^{[2]}$ In any histopathological examination there are mainly two components for the diagnosis. One is macroscopic or gross examination. Second is microscopic examination. ${ }^{[3]}$ In some cases the histopathological examination adds some value in determining the possible causes of recurrent pregnancy loss or it may show some unexpected pathology. At our centre too, it is a routine practice to submit tissues obtained by uterine evacuation to the histopathology department, and to confirm the presence of intrauterine fetal tissue. Hence this present study was undertaken to determine the spectrum of histopathological changes seen in first trimester abortion and also to correlate it clinically.

\section{Materials and Methods}

The present retrospective study was done for a period of one year in the department of Pathology, Gujarat Adani institute of Medical Sciences, G. K General Hospital, Bhuj. Total 62 samples of uterine evacuation products were evaluated. Clinical data including age, parity, gestational age and clinical diagnosis was recorded. All the tissues obtained were placed in jar or sterile container containing $10 \%$ formalin and sent to the histopathology department where further processing was done. Hematoxylin and eosin stain was done as per recommended protocol ${ }^{[4]}$ and microscopic examination was done. Along with their clinico-pathological correlation the histopathological spectrum of the lesions were also studied and the necessary statistical analysis was done. 


\section{Result}

In the present study out of 62 cases of uterine evacuation products, the most common group affected was 20-30years (46\%) followed by $30-40$ years $(17 \%)$. (Table 1$)$

The most common clinical diagnosis was retained product of conception (34\%), followed by hydatidiform mole (24\%). (Table 2)

The most common histological finding was presence of chorionic villi (55\%), followed by presence hydatidiform mole (24\%). (Table 3)

The histopathological examination of the products of conception showed the presence of chorionic villi in various planes of section with the presence of maternal blood in surrounding lacunae. These chorionic villi show the presence of trophoblastic cells (cytotrophoblastic and syncytotrophoblastic). (Figure 1)
The histopathological examination of the hydatidiform mole showed diffuse enlargement of villi with marked hydropic changes, at some places cistern formation and area of marked cytological atypia was present. (Figure $2 \& 3$ )

Hydatidiform mole on gross examination is having classical bunch of grapes appearance with presence of blood clots. The individual vesicles measure from $2 \mathrm{~mm}$ to $20 \mathrm{~mm}$. Total measurement is $15 \times 13 \mathrm{~cm}$, weighing 350 gm. (Figure 4)

Decidual reaction shows sheets of decidual cells having characteristic polygonal cells with abundant pale to eosinophilic granular cytoplasm and round to oval bland nuclei with prominent nucleoli. (Figure 5)

Clinico-pathological correlation was found in 49/62 cases (79\%). Most common clinico-pathological correlation was found in product of conception followed by hydatidiform mole.

Table 1: Age wise distribution.

\begin{tabular}{|c|c|c|}
\hline Age Group (years) & Number of cases & Percentage (\%) \\
\hline $10-20$ & 10 & $17 \%$ \\
\hline $20-30$ & 29 & $46 \%$ \\
\hline $30-40$ & 12 & $20 \%$ \\
\hline $40-50$ & 11 & $17 \%$ \\
\hline Total number & 62 & \\
\hline
\end{tabular}

Table 2: Clinical diagnosis of uterine evacuation products.

\begin{tabular}{|l|c|c|}
\hline Clinical diagnosis & Total number of cases & Percentages (\%) \\
\hline Retained product of conception & 21 & 24 \\
\hline Hydatidiform Mole & 15 & 15 \\
\hline Tubal Ectopic pregnancy & 9 & 15 \\
\hline Dysfunctional uterine bleeding (DUB) & 9 & 3 \\
\hline Ovarian ectopic pregnancy & 2 & 3 \\
\hline Missed abortion & 2 & 1 \\
\hline Septic abortion & 1 & 1 \\
\hline Blighted ovum & 1 & 1 \\
\hline Incomplete abortion & 1 & 1 \\
\hline Rudimentary horn & 1 & \\
\hline Total number & 62 & \\
\hline
\end{tabular}

Table 3: Histopathological diagnosis of uterine evacuation products.

\begin{tabular}{|l|c|c|}
\hline Histopathological diagnosis & Number of cases & Percentage \\
\hline Chorionic villi & 34 & 24 \\
\hline Hydatidiform mole & 15 & 10 \\
\hline Decidual reaction & 6 & 8 \\
\hline Chorionic villi with inflammation & 5 & 3 \\
\hline Hemorrhage & 2 & \\
\hline Total number & 62 & \\
\hline
\end{tabular}




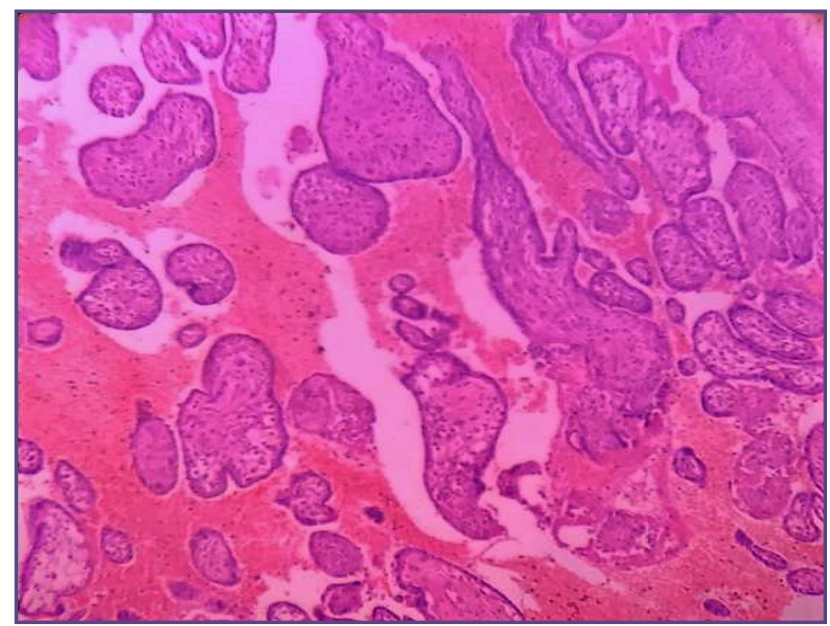

Fig. 1: Shows varying size of chorionic villi and maternal blood in surrounding lacunae.

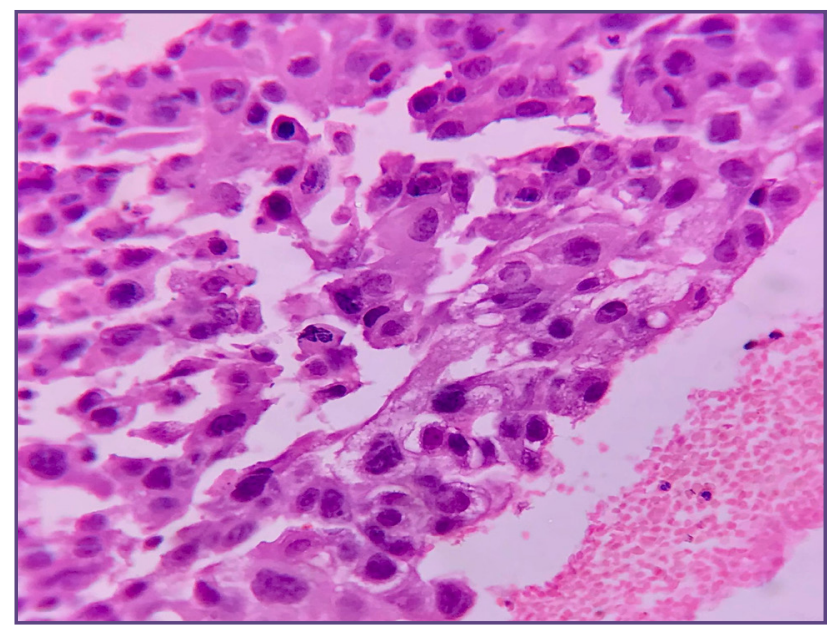

Fig. 3: shows marked cellular atypia in hydatidiform mole. (H\&E, 400X).

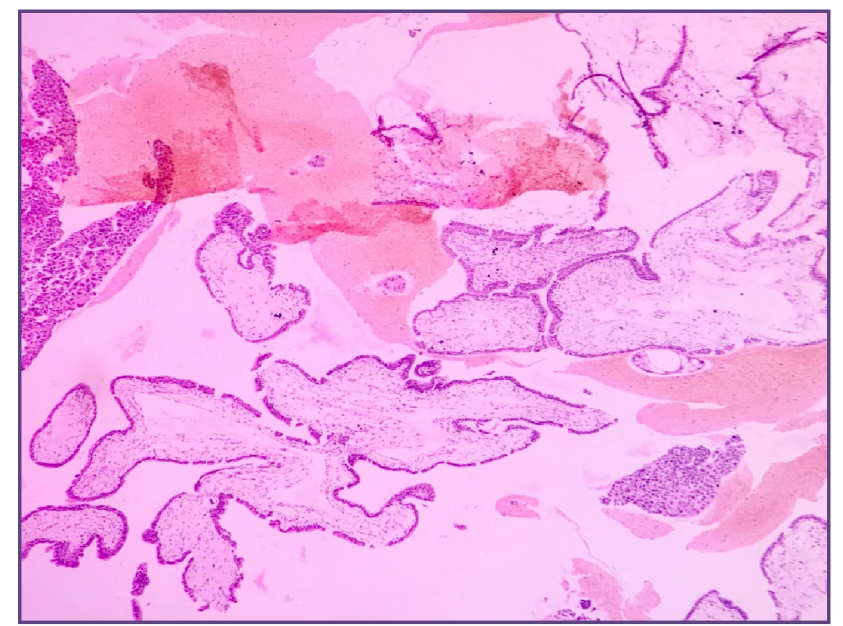

Fig. 2: Shows diffuse enlargement of villi with hydropic changes (H\& E, 100X).

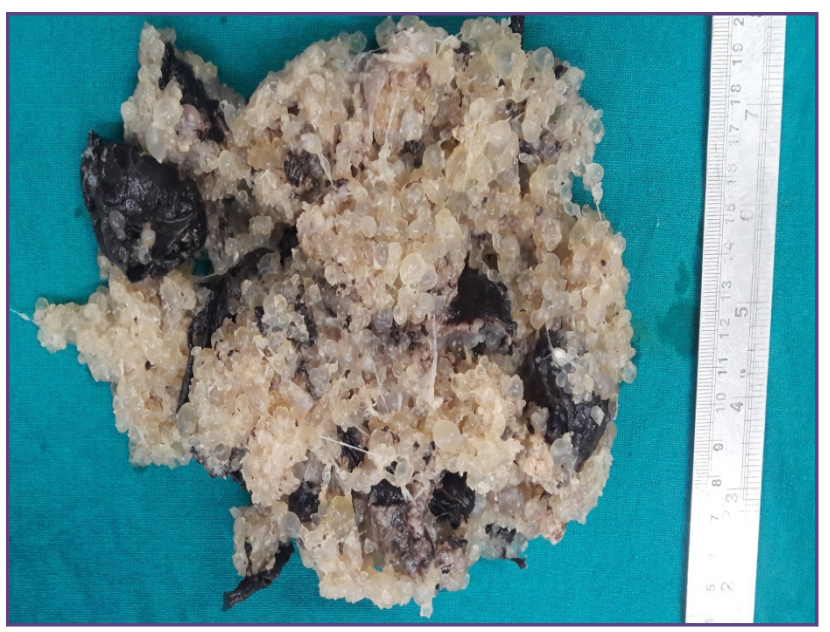

Fig. 4: Shows specimen of hydatidiform mole, grape like varying sizes of vesicles are seen.

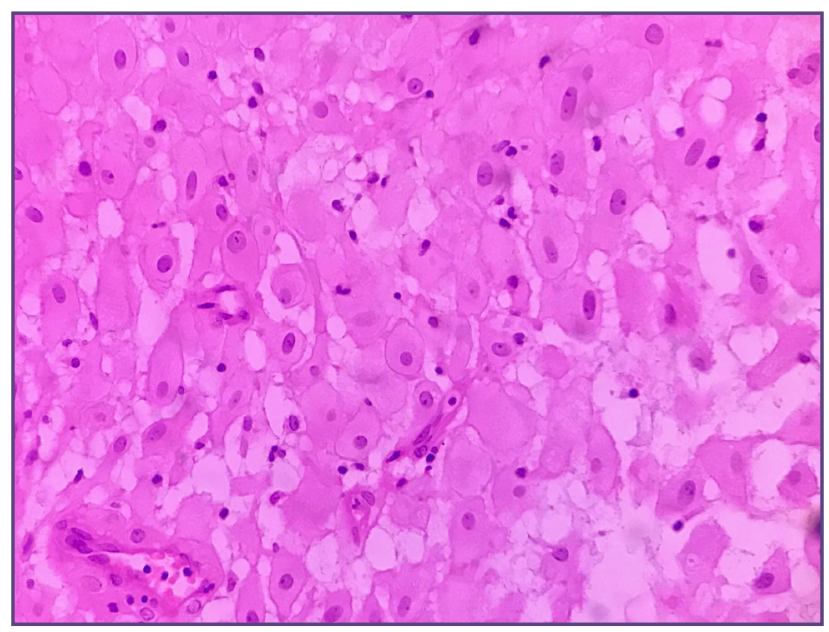

Fig. 5 : Shows clusters of Decidual cells and absence of chorionic villi (H\&E, 400X). 


\section{Discussion}

According to WHO in 1977, the definition of Abortion is, "Expulsion or excretion from its mother a fetus or embryo weighing 500 gm or less". ${ }^{[5]}$ Recently the definition of abortion is given as a spontaneous loss of a pregnancy before the fetus is sufficiently developed to survive outside the mother. ${ }^{[5]}$ As miscarriage is one of the common problems in early pregnancy accurate diagnosis is essential for the treatment and management of the patients. The diagnostic tools for the miscarriage is a triad including radiological examination mainly ultra sonography, biochemical marker quantitative beta human chorionic gonadotropin (beta hCG) and histopathological examination. ${ }^{[6]}$ In our study we agree with Novak et a ${ }^{[7]}$ that all the specimens should be submitted to histopathological examination to investigate whether the abortion was due to dysmorphic, disruptive causes and to exclude the presence of trophoblastic disease and sometimes simply to confirm that pregnancy has occurred by showing presence of fatal or placental tissue. Some other studies also agree with the study of Novak et al ${ }^{[7]}$ that all specimens should be submitted for histopathological evaluation. ${ }^{[8,9,10,11]}$ Heath et al ${ }^{[12]}$ recommended that histopathological examination of uterine evacuation products should not be routinely done at surgical termination of pregnancy because they detected only two partial mole in 1576 cases. They also recommend that histopathological examination is to be performed only for women with uncertain operative diagnosis or when less tissue than expected is obtained or when trophoblastic tissue are not readily identified at surgery, or if the routine inspection of the tissue suggests that there is unexpected pathology. Though, we disagree with this school of thought. In the present study out of 62 cases, chorionic villi was found in $34(55 \%)$ of the cases (Table $3 \&$ Figure 1). Out of these, tertiary stage were found in 14/34 cases (41\%), secondary stage $11 / 34$ cases $(32 \%)$ and primary stage $6 / 34$ cases $(18 \%)$. Chorionic villi with inflammatory changes were found in $5 / 62$ cases (8\%). In the study of Fram et al ${ }^{[3]}$ study chorionic villi was found in $66 \%$ cases. In the present study hydatidiform mole was found in 15/62 cases (24\%) (Figure 2, 3 \& 4), in which partial mole was found in $6 / 15$ cases $(40 \%)$ and complete mole in $9 / 15$ cases $(60 \%)$. While in one other study $^{[12]}$ the histopathological review of 670 unselected cases showed $18 \%$ cases of the patient with unsuspected molar pregnancy. Similarly El Halaby et al ${ }^{[9]}$ reported molar pregnancy in $4.3 \%$ cases and Fram et al ${ }^{[3]}$ reported partial mole and molar pregnancy in total $18 \%$ of the cases in their study. Following the molar pregnancy the follow up of patient with beta human chorionic gonadotrophin ( hCG )level should be done. ${ }^{[13]}$ In present study decidual changes was found in $6 / 62$ cases $(10 \%)$ and in Fram et al ${ }^{[3]}$ it was found in $7 \%$ of the cases. The presence of decidual changes indicates necessity of further evaluation of these patients. This aids into the diagnosis of product of conception and at times an unexpected conditions like molar pregnancy. Only hemorrhage was found in two cases. Incomplete evacuation in such cases can lead to false negative reports. The clinico-pathological discordance was present in $21 \%$ of cases. The most common cause was DUB followed by tubal ectopic pregnancy and rudimentary horn of the uterus. In one case in which the clinical diagnosis of DUB was rendered the histopathological examination revealed the presence of partial mole.

\section{Conclusion}

The present study was to highlight the importance of histopathological evaluation of the uterine evacuation products. Histopathology is the gold standard to evaluate the presence of intra uterine gestation, gestational trophoblastic disease and to some extent carcinomas. Hence our study strongly recommends the histopathological examination of all uterine evacuation products as it aids in timely management of the patients.

\section{Acknowledgements}

To all our patients

\section{Funding}

NIL

\section{Competing Interests}

NIL

\section{Reference}

1. Rosai J. Female Reproductive System, Rosai and Ackerman's Surgical Pathology, 10th ed. Maryland Height, Missouri: Mosby; 2011. p. 1637-9.

2. Alsibiani SA. Value of histopathologic examination of uterine products after first-trimester miscarriage. BioMed Res Int 2014; 20(4):52-9.

3. Fram KM. Histological analysis of the products of conception following first trimester abortion at Jordan University Hospital. Eur J Obst Gyn Reproduc Biol 2002; 105(2):147-9.

4. Bancroft J D, Gamble M. In theory and practice of histological techniques. 6th ed 2007:121-34

5. Bennet MJ. Abortion (Essentials of Obstet Gynecol) edited by W.B. Saunders Company: 3rd ed. 1998. p 477-87

6. Rashid P A. The role of histopathological examination of the products of conception following first trimester miscarriage in Erbil Maternity Hospital. Zanco J. Med. Sci. 2017;21(3):1938-42 
7. Novak RW, Malone JM, Robinson HB. The role of histopathologist in the evaluation of first trimester abortion. Patrol annu 1990;25:297-311

8. Fulcheri E, Di CE, Ragni N. Histologic examination of products of conception at the time of pregnancy termination. Int J Gyn Obst 2003; 80(3):315-6.

9. El-Halaby O, AbdElaziz O, Elkelani O, Abo Elnaser M, Sanad Z, Samaka R. The value of routine histopathological examination of products of conception in case of first trimester spontaneous miscarriage. Tanta Medical Science J 2006; 1(4):83-8.

10. Hinshaw K, Fayyad A, Munjuluri P. The management of early pregnancy loss. Revised Guideline no. 25. Green-top Guideline no. 25, Guidelines and Audit Committee of the Royal College of Obstetricians and Gynaecologists2006.
(Available from: http://www.rcog.org.uk/womens-health/ clinical-guidance/ management-early-pregnancy-lossgreen-top-25) Accessed July 5,

11. Health MK, Chark J. The value of histopathological examination of conceptual products. Br J Obstet Gynecol 1995;335:1074-76

12. Heath V, Chadwik V, Cooke I, Manel S, Mackenzie IZ. Should tissue from pregnancy termination and uterine evacuation routinely be examined histologically. $\mathrm{Br} \mathrm{J}$ Obstet Gynecol 2000;107:727-30

13. Whittaker PG, Taylor A. Unsuspected pregnancy loss in healthy women. Lancet 1983;1126-31

14. Paradinas FJ. The diagnosis and prognosis of molar pregnancy: the experience of the National Referral Center in London. Int J Obstet Gynecol 1998;60(1):57-64.

*Corresponding author:

Dr. Riti T.K Sinha, Associate Professor, Department of Pathology, Gujarat Adani Institute of Medical Sciences, Bhuj, Gujarat, India. 370001

Phone: +919641429455

Email: rsinha75@gmail.com

Financial or other Competing Interests: None. 